\title{
Ratio of microRNA-122/155 in isoniazid-induced acute liver injury in mice
}

\author{
LEI SONG ${ }^{1,2}$, ZHONGRUI ZHANG ${ }^{1}$, JINLING ZHANG $^{1}$, XUEBIN ZHU ${ }^{1}$, \\ LEI HE ${ }^{1}$, ZHE SHI $^{1}$, LI GAO ${ }^{1}$ and FUMIN FENG ${ }^{1}$ \\ ${ }^{1}$ Key Laboratory of Coal Mine Health and Safety, School of Public Health, North China University of Science and Technology, \\ Tangshan, Hebei 063000; ${ }^{2}$ Bayan Nur Center for Disease Control and Prevention, \\ Bayan Nur, Inner Mongolia 015000, P.R. China
}

Received May 16, 2015; Accepted January 15, 2016

DOI: $10.3892 /$ etm.2016.3375

\begin{abstract}
Liver injury is a major hindrance to the treatment of tuberculosis (TB) patients due to the primary side effects associated with anti-TB drugs. Several investigations have identified sensitive biomarkers for the early diagnosis of anti-TB drug-induced liver injury (ADLI), including the use of microRNAs (miRNAs/miRs). However, the association between miR-122/155 and ADLI remains unknown. Thus, the present study used reverse transcription-quantitative polymerase chain reaction to observe changes in tissue miR-122/155 expression levels during the course of liver injury in mice. Liver injury was induced by the administration of isoniazid (INH), a first-line anti-TB drug. miR-122/155 expression levels were quantified at seven time points throughout 1 day $(0.25,0.75,1.5,6,12,18$ and $24 \mathrm{~h}$ ) based on the pharmacokinetics of INH in mice. Notably, over the timecourse of INH-induced liver injury, the tissue miR-122 expression level significantly decreased at $0.25 \mathrm{~h}$, which is the peak concentration time of INH, compared with the control group $(\mathrm{P}<0.05)$. The change was more rapid than that of the serum aminotransferase and miR-155, which were significantly increased at $0.75 \mathrm{~h}$. In addition, the pathological score correlated with the ratio of miR-122/miR-155 ( $\mathrm{r}=-0.779$; $\mathrm{P}<0.01)$. In conclusion, the miR-122/155 ratio may be utilized as a sensitive biomarker for ADLI, which could contribute to the early diagnosis of patients following anti-TB treatment.
\end{abstract}

\section{Introduction}

Tuberculosis (TB), which is a chronic infectious disease caused by Mycobacterium tuberculosis, is a global burden, with

Correspondence to: Professor Fumin Feng, Key Laboratory of Coal Mine Health and Safety, School of Public Health, North China University of Science and Technology, 57 Jian-She Road, Tangshan, Hebei 063000, P.R. China

E-mail: fm_feng@sina.com

Key words: antituberculosis drug-induced liver injury, epigenetics, microRNAs, microRNA-122, microRNA-155, isoniazid
8.7 million new cases and 1.4 million mortalities reported in 2011 (1). Anti-TB drug-induced liver injury (ADLI) is a severe adverse effect of TB treatment and may negatively affect treatment compliance.

Isoniazid (INH) is a first-line therapy for the treatment of TB, however, hepatotoxicity is a frequently observed side effect of INH that may progress into liver cirrhosis (2).

The current biomarkers for liver injury [serum alanine aminotransferase (ALT) and aspartate aminotransferase (AST)] are adequate indicators of damage or altered liver function (3). However, the aforementioned parameters are unable to conclusively identify liver injury. In addition, serum ALT and AST activity also increase following the injury of other organs, and therefore are not selective for liver injury (4). Thus, gene expression variations are preferable for the classification of hepatotoxicants (5). Our previous study used epigenetics to identify that DNA methylation is a more sensitive marker for the detection of ADLI (6). Furthermore, recent studies have revealed that microRNA ( $\mathrm{miRNA} / \mathrm{miR}$ ) may be used as a novel biomarker for mRNA regulatory genes $(7,8)$.

miRNAs are small (18-25 nt) endogenous, non-coding RNA molecules that regulate post-transcriptional gene expression through RNA interference, or through inhibition of translational initiation and progression (9). Over $30 \%$ of mammalian genes are regulated by miRNA (10); therefore, miRNAs are important in a wide variety of physiological and pathological processes (11). It has been reported that miRNA expression levels differ significantly in various diseases, indicating the potential for their use as biomarkers (12-14).

Among miRNAs, miR-122, which accounts for $\sim 70 \%$ of the total miRNA in the adult liver, is associated with liver biology and disease, including cell cycle progression, hepatocellular carcinogenesis (15), lipid metabolism (16) and fibrosis (17). Furthermore, miR-122 has been confirmed as a potential biomarker for the diagnosis of hepatotoxicity caused by acetaminophen (18) and alcohol (19). In addition, miR-155 is a multi-functional miRNA known to have a regulatory role in numerous biological processes, including immunity (20), inflammation (21), atherosclerosis (22) and cancer (23). However, it has been demonstrated that liver tissue miR-155 expression levels are increased in non-alcoholic steatohepatitis and hepatocellular carcinoma, and the expression levels 
were associated with disease severity $(24,25)$. These findings suggest a strong association between the miR-122/155 ratio and liver injury. Although much is known concerning the effects of liver injury, information on miR-122/155 expression and ADLI remains limited.

miR-122/155 regulate a large number of genes and consequently are involved in numerous biological processes, including the response to environmental chemicals. Therefore, the present study hypothesized that the levels of miR-122/155 in the liver tissue and blood may serve as a biomarker for ADLI. Consequently, miR-122/155 expression levels in the liver tissue of mice with INH-induced ADLI were analyzed to identify changes in miR-122/155 expression levels over a 24-h period. The aim of this was to confirm the effectiveness of the miR-122/155 ratio as quantitative marker for ADLI.

\section{Materials and methods}

Animals. A total of 64 Kunming mice ( 32 males and 32 females; 5 weeks old; body weight, $18-22 \mathrm{~g}$; certificate no. 2009-0004) were obtained from Beijing HFK Bioscience Co., Ltd. (Beijing, China). The present study was approved by the ethics committee of North China University of Science and Technology (Tangshan, China). To establish the ADLI models, mice were orally administered INH $(0.2 \mathrm{ml} /$ mouse; $180 \mathrm{mg} / \mathrm{kg}$ body weight; Shenyang Hongqi Pharmaceutical Co., Ltd., Liaoning, China; batch no. 1204081) dissolved in double-distilled water $\left(\mathrm{ddH}_{2} 0\right)$ to a final concentration of $18 \mathrm{mg} / \mathrm{ml}$. Blood and liver tissue samples were collected at $0.25,0.75,1.5,6,12,18$ and $24 \mathrm{~h}$ following the administration of INH or $\mathrm{ddH}_{2} \mathrm{O}$ (control group; $\mathrm{n}=8$ per time point/group). In order to harvest the liver, the mice were sacrificed by cervical dislocation. The blood samples were centrifuged at $1,370 \mathrm{xg}$ for $10 \mathrm{~min}$ at $4^{\circ} \mathrm{C}$, and the serum was collected and stored at $-80^{\circ} \mathrm{C}$ until use. A section of the liver from the porta hepatis was fixed in 10\% neutral buffered formalin (Tianjin Kemiou Chemical Reagent Co., Ltd., Tianjin, China) and the remaining liver was preserved at $-80^{\circ} \mathrm{C}$.

Reverse transcription-quantitative polymerase chain reaction (RT-qPCR). Total RNA was isolated from the livers of mice using a benchtop homogenizer (no. TGL-16B; Shanghai Anting Scientific Instrument Factory, Shanghai, China) with TRIzol $^{\circledR}$ reagent (cat no. 15596-018; Invitrogen; Thermo Fisher Scientific, Inc., Waltham, MA, USA), according to the manufacturer's protocol. The total RNA concentration was quantified using a UV-VIS spectrophotometer (product no. TU-1901; Beijing Purkinje General Instrument Co., Ltd. Beijing, China). The RNA quality and integrity was assessed by measuring the absorbance ratio at 260 and $280 \mathrm{~nm}$, and by performing $1 \%$ agarose gel electrophoresis. RNA was reverse transcribed into cDNA using miR-122/155 and U6-specific RT primers and the TaqMan MicroRNA Reverse Transcription kit (product no. 4366596; Applied Biosystems; Thermo Fisher Scientific, Inc.) on a C1000 Touch Thermo Cycler (Bio-Rad Laboratories, Inc., Hercules, CA, USA), according to the manufacturer's protocols. The cycling conditions for the RT reaction were as follows: $16^{\circ} \mathrm{C}$ for $30 \mathrm{~min}, 42^{\circ} \mathrm{C}$ for $30 \mathrm{~min}, 85^{\circ} \mathrm{C}$ for $5 \mathrm{~min}$ and $4^{\circ} \mathrm{C}$ for $1 \mathrm{~min}$. The presence of miR-122/155 was confirmed using Platinum SYBR Green
qPCR SuperMix-UDG (cat no. 11733-038; Invitrogen; Thermo Fisher Scientific, Inc, Waltham, MA, USA) on a StepOnePlus Real-Time PCR System (Applied Biosystems; Thermo Fisher Scientific, Inc.). U6 small nuclear RNA (snRNA) was used as the miRNA internal control. The primers were designed using Primer Premier software (version 5.0; Premier Biosoft International, Palo Alto, CA, USA) and were synthesized by Invitrogen (Thermo Fisher Scientific, Inc.). The primer and probe sequences for the RT-qPCR are presented in Table I. The PCR cycling conditions were as follows: $50^{\circ} \mathrm{C}$ for $1 \mathrm{~min}$, followed by 40 cycles of $95^{\circ} \mathrm{C}$ for $15 \mathrm{sec}$ and $60^{\circ} \mathrm{C}$ for $1 \mathrm{~min}$. Relative miRNA production was calculated using the $2^{-\Delta \Delta C q}$ method (26), where $\mathrm{C}_{\mathrm{q}}$ is the quantification cycle. All reactions were run in triplicate, and the results were normalized to U6 snRNA.

Biochemical assay and pathological examination. Serum ALT and AST levels were determined using an automatic biochemical analyzer (no. 7180; Hitachi, Tokyo, Japan), according to the manufacturer's protocol. Formalin-fixed samples were embedded in paraffin, sectioned (4- $\mu \mathrm{m}$ thickness), and stained with hematoxylin and eosin (H\&E; Beijing Solarbio Science \& Technology Co., Ltd., Beijing, China) for microscopic examination (CX21; Olympus Corporation, Tokyo, Japan). The degree of liver tissue injury was determined using a semi-quantitative method (27), in which the liver lesion severity number was multiplied by the weighted coefficient. The liver lesion severity numbers were as follows: Hepatocellular congestion, hemorrhage, 1 ; hepatocyte degeneration water, 1 ; inflammatory cell infiltration, 1 ; and hepatocyte necrosis, 3 . The degree of liver injury was then calculated.

Statistical analysis. The data are expressed as the mean \pm standard deviation. Statistical differences between groups were determined using Student's t-tests. Multiple group comparisons were performed using analysis of variance in combination with a Tukey's or Dunnett's post-hoc test. Statistical analyses were conducted using SPSS software, version 17 (SPSS, Inc., Chicago, IL, USA). P $<0.05$ was considered to indicate a statistically significant difference.

\section{Results}

Histopathology and biochemistry of mouse liver. Histological examinations were performed on liver specimens (Fig. 1A-H) and the associated scores of the liver injury are displayed in Fig. 2. The livers of the INH-treated mice exhibited evidence of damaged cells from the $0.25 \mathrm{~h}$ time point (Figs. 1B and 2). Thus, an INH-induced liver injury model was established. Furthermore, at the $0.75 \mathrm{~h}$ time point, evidence of inflammatory cell infiltration was observed (Fig. 1C).

The serum ALT and AST levels (Fig. 3) were increased at different time points of INH-induced liver injury (Fig. 3). The serum ALT and AST levels were significantly higher 0.75 and $1.5 \mathrm{~h}$ after INH administration compared with the control group ( $\mathrm{P}<0.05$; Fig. 3 ), however, liver injury was observed from $0.25 \mathrm{~h}$ onwards (Fig. 2).

Thus, the present study determined that the variations in serum ALT and AST occur subsequent to the histopathological changes caused by INH-induced liver injury. 
Table I. RT-qPCR primer and probe sequences.

\begin{tabular}{ll}
\hline Gene & \multicolumn{1}{c}{ Primer/Probe } \\
\hline RT & \\
miR-122 & 5'-ACAATGGTGTTTGTGTCCAAACCACAAACACCATTGTCA-3' \\
miR-155 & 5'-ATAGGGGTTTTGGCCTCTGACTGACTCCTAATCACAATTAGC-3' \\
U6 & 5'-ATGGAACGCTTCACGAATTTGCGTGTCATCC-3' \\
qPCR & \\
miR-122 & F: 5'-GCAGCTGTGGAGTGACAATGG-3' \\
miR-155 & F: 5'-GCCTGTTAAGCTAATTGTGAT-3' \\
miR-122/155 & R: 5'-GTGCAGGGTCCGAGGT-3' \\
U6 & F: 5'-GCAAGGATGACACGCAAT-3' \\
& R: 5'-ATGGAACGCTTCACGAAT-3' \\
\hline
\end{tabular}

RT-qPCR, reverse transcription-quantitative polymerase chain reaction; miR, microRNA; F, forward; R, reverse.

Table II. Association between pathological changes and liver injury score.

\begin{tabular}{llllll}
\hline Liver injury score correlation & ALT & AST & miR-122 & miR-155 & miR-122/miR-155 \\
\hline r-value & 0.157 & 0.053 & -0.592 & 0.678 & -0.779 \\
P-value & 0.215 & 0.678 & $0.001^{\mathrm{a}}$ & $0.001^{\mathrm{a}}$ & $0.001^{\mathrm{a}}$ \\
\hline
\end{tabular}

${ }^{a} \mathrm{P}<0.05$ vs. the control. ALT, alanine aminotransferase; AST, aspartate aminotransferase; miR, microRNA.

A

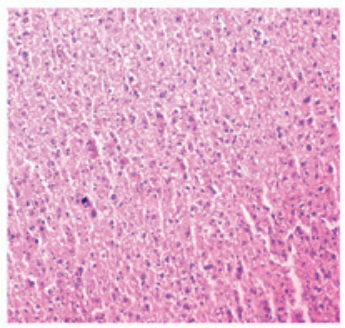

$\mathbf{E}$

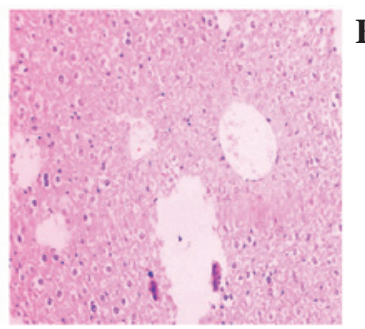

B
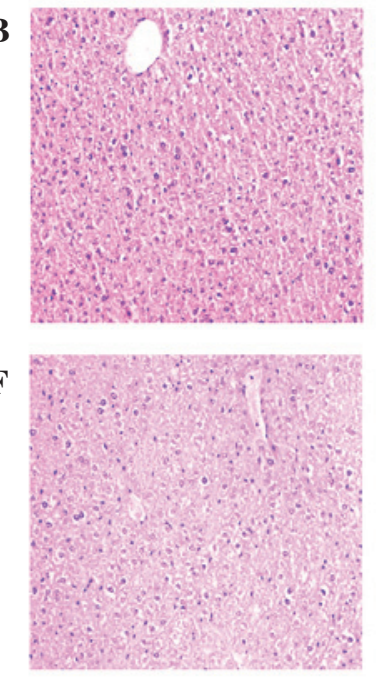

C
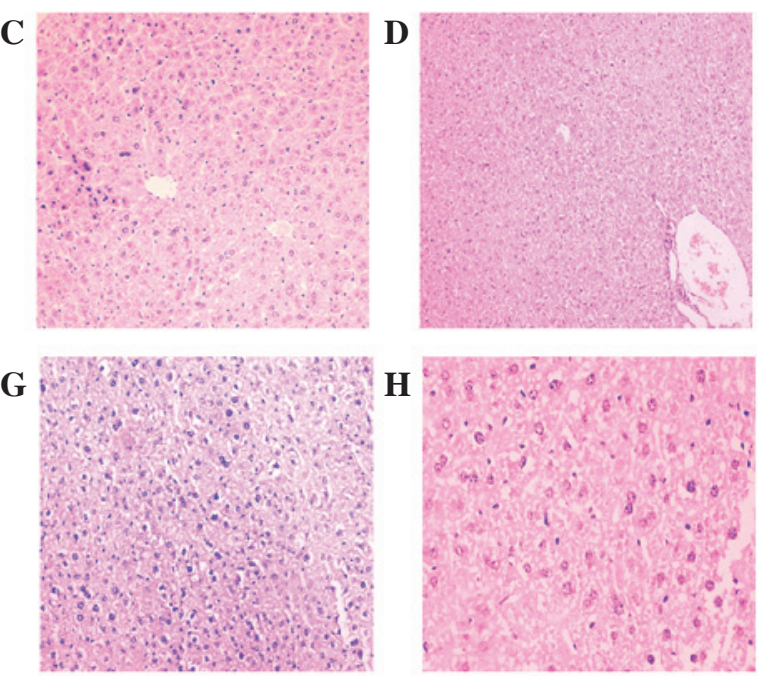

Figure 1. Representative hematoxylin and eosin-stained liver sections from (A) control mice and mice treated with isoniazid (180 mg/kg) for (B) 0.25 , (C) 0.75 , (D) $1.5,(\mathrm{E}) 6,(\mathrm{~F}) 12,(\mathrm{G}) 18$ and (H) $24 \mathrm{~h}$ (original magnification, x100).

Changes in tissue miR-122/155 expression in mice with INH-induced liver injury. miR-122/155 expression levels were observed in the mice liver the tissues over a 24 -h period (Fig. 4). The miR-122 levels were significantly declined at $0.25 \mathrm{~h}$, with a $56.50 \pm 27.77 \%$-fold decrease observed compared with the control $(\mathrm{P}<0.05)$. Although the expression levels of miR-122 were marginally increased at the other time points, they were immediately followed by small declines in expression, and the expression levels remained lower, as compared with the control
(Fig. 4A). These results suggest that miR-122 expression levels decline during INH-induced liver injury. Conversely, miR-155 levels were significantly increased at $0.75 \mathrm{~h}(11.25 \pm 1.43 \%$-fold increase; $\mathrm{P}<0.05)$ and reached peak expression levels at the 12-h time point (39.04 $\pm 4.10 \%$-fold increase; $\mathrm{P}<0.01$; Fig. $4 \mathrm{~B})$. These results suggest that tissue miR-155 expression levels are elevated during INH-induced liver injury. Notably, the expression levels of miR-122 were altered more rapidly in response to INH-induced liver injury, as compared with miR-155 (Fig. 4C). 


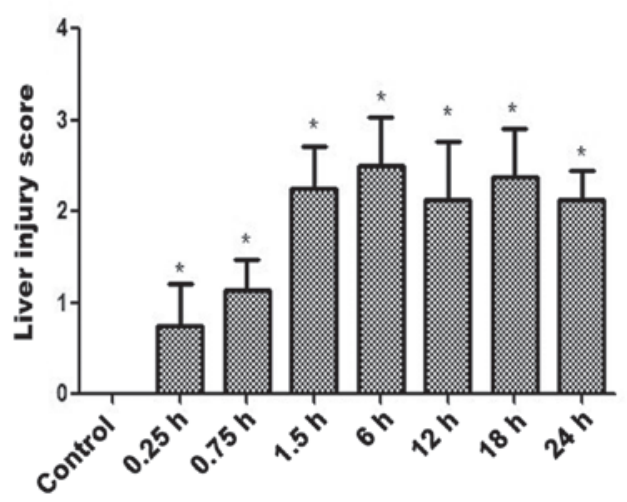

Figure 2. Liver injury score of 80 mice at various time points throughout a 24-h period following the oral administration of INH $(180 \mathrm{mg} / \mathrm{kg})$. The liver injury score was determined by a semi-quantitative method. Data are presented as mean \pm standard deviation. ${ }^{*} \mathrm{P}<0.05$ vs. control.

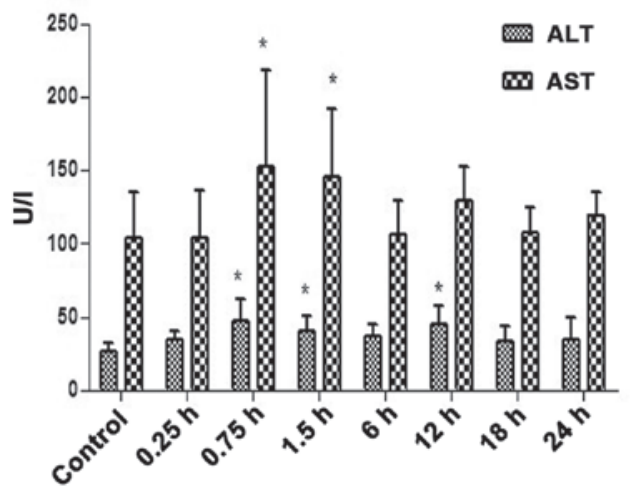

Figure 3. Serum ALT and AST levels in 80 mice at various time points throughout a 24-h period following the oral administration of INH $(180 \mathrm{mg} / \mathrm{kg})$. The levels of ALT and AST were determined using an automatic biochemical analyzer. Data are presented as mean \pm standard deviation. ${ }^{*} \mathrm{P}<0.05$ vs. control. ALT, alanine aminotransferase; AST, aspartate aminotransferase.

Correlation of pathological and biochemical changes with INH-induced liver injury. Liver injury score was correlated to changes in biochemistry over the 24-h period during INH-induced liver injury. An association was observed between liver injury score and the following: miR-122 expression, miR-155 expression, the ratio of miR-122/155 and the ratio of miR-155/122, in which the ratio of miR-122/155 exhibited the most significant correlation $(r=-0.779$; $\mathrm{P}<0.001)$. However, liver injury scores revealed no correlation with ALT or AST. In conclusion, the ratio of miR-122/155 has a greater degree of correlation with liver damage compared with ALT, AST, miR-122 and miR-155 expression (Table II).

\section{Discussion}

miRNAs are important in a wide variety of physiological and pathological processes (28). Recently, miRNAs have been revealed as potential biomarkers for the diagnosis of several diseases. In the present study, tissue miR-122 was examined as a potential marker of hepatocyte damage, and miR-155 as a marker of inflammation in INH-induced liver injury. A mouse model of INH-induced liver injury was established and
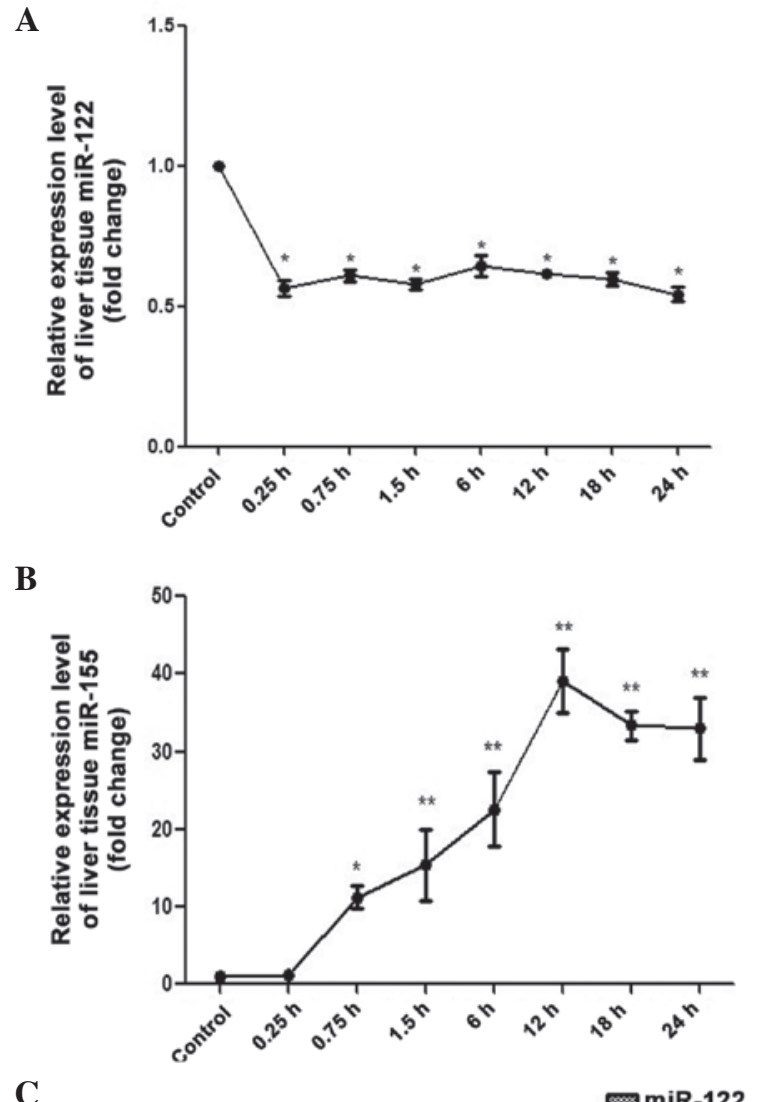

C

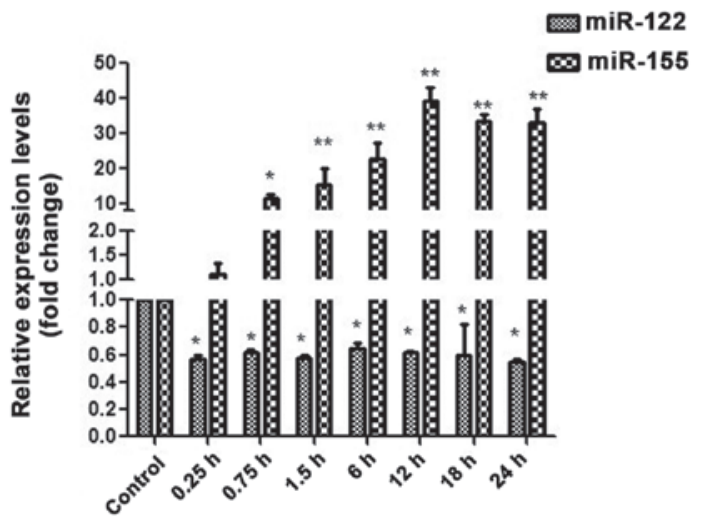

Figure 4. Relative (A) miR-122 and (B) miR-155 expression levels in 80 mice at various time points throughout a 24 -h period following the oral administration of INH $(180 \mathrm{mg} / \mathrm{kg})$. (C) A comparison of the expression levels of miR-122 and miR-155 in response to INH-induced liver injury. Abundance of miR-122 and miR-155 was measured by reverse transcription-quantitative polymerase chain reaction following normalization with U6 small nuclear RNA. Data are presented as mean \pm standard deviation. ${ }^{*} \mathrm{P}<0.05,{ }^{* *} \mathrm{P}<0.01$ vs. control. miR, microRNA.

changes in tissue miR-122/155 expression levels at different time points during liver injury were analyzed.

Changes in miR-122/155 expression levels in INH-induced liver injury were recorded at seven time points $(0.25,0.75,1.5,6$, 12,18 and $24 \mathrm{~h}$ ) based on the known pharmacokinetics of INH in mice (29). Double the recommended dosage for humans for was administered to replicate the initial dosing administered to humans in clinical treatment. The present study identified that tissue miR-122/155 expression levels significantly changed during liver injury. Compared with the control group, tissue miR-122 expression levels decreased during INH-induced liver injury. In a previous study involving the use of a mouse 
model administered with acetaminophen, miR-122 expression levels in the tissue were also observed to decrease (30). The aforementioned study also indicated that the damaged cells within the liver tissue resulted in the transport or release of cellular miRNAs into the peripheral circulation (30). Notably, in the present study, tissue miR-122 expression levels initially decreased and initiated two upward trends after $0.25 \mathrm{~h}$ and $1.5 \mathrm{~h}$. The aforementioned change may be a result of the pharmacokinetics of INH, as the peak concentration times of INH and its metabolite hydrazine, which are the primary chemical substances that give rise to INH-induced liver injury, are $0.25 \mathrm{~h}$ and $1.5 \mathrm{~h}$, respectively (29). As the peak concentration times correspond to the increase in miR-122 expression levels, we hypothesize that there may be an association between miR-122 and the peak concentration times of INH; however, further investigation is required .

The target genes of miR-155, including interleukin-1 and v-ets avian erythroblastosis virus E26 oncogene homolog 1, are associated with the immune and hematopoietic systems $(31,32)$. To investigate the role of miR-155 during liver injury, the present study examined the dynamic changes in miR-155 expression levels in the livers of mice with INH-induced liver injury. Liver tissues were observed under a microscope with $H \& E$ staining to investigate the inflammatory response at $0.25 \mathrm{~h}$. miR-155 expression levels displayed an overall upward trend in the present study, suggesting that tissue miR-155 expression levels increase during inflammatory responses, reaching peak levels at $12 \mathrm{~h}$ and declining thereafter. Notably, the changes in miR-155 expression occur later than those of miR-122, which may be a result of the complex internal environment. An association between miR-155 and inflammatory factors was also observed in the present study. miR-155 has previously been demonstrated to promote autoimmune inflammation in inflammatory responses (33) and is upregulated in macrophages following stimulation by affecting inflammatory mediators (34). A further study determined that miR-155 was able to influence tumor necrosis factor- $\alpha$ expression levels to increase inflammatory injury through adjusting fas-associated death domain and inhibitor of $\kappa \mathrm{B}$ expression (35). Furthermore, it was revealed that inflammatory mediators and miR-155 can influence one another's expression levels (36).

Currently, elevated serum levels of ALT and AST are used as a diagnosis of liver injury; however, their levels are also increased in other diseases, and differences in the levels of ALT and AST may occur later in the serum, as compared with the liver (37). Previous studies have demonstrated that miR-122 expression levels have a greater association with liver injury than serum ALT and AST levels; thus, miR-122 is a potential biomarker for the diagnosis of liver injury (38). In the current study, changes in miR-122 expression levels occurred prior to changes in serum ALT and AST levels. Previous evidence revealed that miR-122 is more sensitive and specific for liver injury compared with ALT and AST (18), which is consistent with the results of the present study. In addition, where the levels of ALT and AST were returned to normal at $6 \mathrm{~h}$, the expression levels of miR-122 and histopathological changes of liver tissue remained unchanged. Therefore, the levels of ALT and AST are unable to accurately reveal the histopathological changes of the liver tissue (39).
At present, the ratio of ALT/AST is used to determine the degree of liver injury. In the present study, the ratio of miR-122/155 was determined by dividing miR-122 expression levels by those of miR-155. The ratio of miR-122/155 was more closely associated with the degree of liver injury than the ALT/AST ratio. miR-122 may indicate the presence of damaged hepatocytes, possibly because miR-122 is expressed by liver cells under normal physiological conditions but declines in the event of liver cell injury (40). miR-155, as an inflammation-specific miRNA, can regulate the expression of inflammatory cells (41). The current study also reported that miR-155 expression levels increase when inflammatory cells invade the liver.

In conclusion, the present study indicates that the ratio of miR-122/155 may be a more accurate biomarker of liver damage in INH-induced acute liver injury than the ratio of ALT/AST. Further studies involving various anti-TB drugs are, however, required to consolidate upon this finding.

\section{Acknowledgements}

The present study was supported by the Key Lab of Tangshan (grant no. 08150201A-1-8).

\section{References}

1. Glaziou P, Falzon D, Floyd K and Raviglione M: Global epidemiology of tuberculosis. Semin Respir Crit Care Med 34: 3-16, 2013.

2. Shih TY, Young TH, Lee HS, Hsieh CB and Hu OY: Protective effects of kaempferol on isoniazid- and rifampicin-induced hepatotoxicity. AAPS J 15: 753-762, 2013.

3. Shi Q, Hong H, Senior J and Tong W: Biomarkers for drug-induced liver injury. Expert Rev Gastroenterol Hepatol 4: 225-234, 2010.

4. Zelber-Sagi S, Toker S, Armon G, Melamed S, Berliner S, Shapira I, Halpern Z, Santo E and Shibolet O: Elevated alanine aminotransferase independently predicts new onset of depression in employees undergoing health screening examinations. Psychol Med 43: 2603-2613,2013.

5. Yang X, Greenhaw J, Shi Q, Su Z, Qian F, Davis K, Mendrick DL and Salminen WF: Identification of urinary microRNA profiles in rats that may diagnose hepatotoxicity. Toxicol Sci 125: 335-344, 2012.

6. Zhang B, Sun S, Shen L, Zu X, Chen Y, Hao J, Huang X and Feng F: DNA methylation in the rat livers induced by low dosage isoniazid treatment. Environ Toxicol Pharmacol 32: 486-490, 2011

7. Duskova K, Nagilla P, Le HS, Iyer P, Thalamuthu A, Martinson J, Bar-Joseph Z, Buchanan W, Rinaldo C and Ayyavoo V: MicroRNA regulation and its effects on cellular transcriptome in human immunodeficiency virus-1 (HIV-1) infected individuals with distinct viral load and CD4 cell counts. BMC Infect Dis 3: 250, 2013

8. Mi SL, Zhang J, Zhang W and Huang RS: Circulating microRNAs as biomarkers for inflammatory diseases. Microrna 2: 64-72, 2013.

9. Henderson MC and Azorsa DO: The genomic and proteomic content of cancer cell-derived exosomes. Front Oncol 2: 38, 2012.

10. Lewis BP, Burge CB and Bartel DP: Conserved seed pairing, often flanked by adenosines, indicates that thousands of human genes are microRNA targets. Cell 120: 15-20, 2005.

11. Wu D and Murashov AK. Molecular mechanisms of peripheral nerve regeneration: Emerging roles of microRNAs. Front 4: 55, 2013.

12. Ulivi P, Foschi G, Mengozzi M, Scarpi E, Silvestrini R, Amadori D and Zoli W: Peripheral blood miR-328 expression as a potential biomarker for the early diagnosis of NSCLC. Int J Mol Sci 14: 10332-10342, 2013.

13. Sita-Lumsden A, Dart DA, Waxman J and Bevan CL. Circulating microRNAs as potential new biomarkers for prostate cancer. $\mathrm{Br}$ J Cancer 108: 1925-1930, 2013. 
14. Giusti I, D'Ascenzo S and Dolo V: Microvesicles as potential ovarian cancer biomarkers. BioMed Res Int 2013: 703048, 2013.

15. Wang B, Wang H and Yang Z: MiR-122 inhibits cell proliferation and tumorigenesis of breast cancer by targeting IGF1R. PLoS One 7: e47053, 2012.

16. Tsai WC, Hsu SD, Hsu CS,Lai TC, Chen SJ, Shen R, Huang Y, Chen HC, Lee CH, Tsai TF, et al: MicroRNA-122 plays a critical role in liver homeostasis and hepatocarcinogenesis. J Clin Invest 22: 2884-2897, 2012

17. Arataki K, Hayes CN, Akamatsu S, Akiyama R, Abe H, Tsuge M, Miki D, Ochi H, Hiraga N, Imamura M et al. Circulating microRNA-22 correlates with microRNA-122 and represents viral replication and liver injury in patients with chronic hepatitis B. J Med Virol 85: 789-798.

18. Antoine DJ, Dear JW, Lewis PS, Platt V, Coyle J, Masson M, Thanacoody RH, Gray AJ, Webb DJ, Moggs JG et al: Mechanistic biomarkers provide early and sensitive detection of acetaminophen-induced acute liver injury at first presentation to hospital. Hepatology 58: 777-787, 2013

19. Zhang Y, Jia Y, Zheng R, Guo Y, Wang Y, Guo H, Fei M and Sun S: Plasma microRNA-122 as a biomarker for viral-, alcohol-, and chemical-related hepatic diseases. Clin Chem 56: 1830-1838, 2010.

20. Lind EF and Ohashi PS: Mir-155, a central modulator of T-cell responses. Eur J Immunol 44: 11-15, 2014.

21. McDaniel K, Herrera L, Zhou T, Francis H, Han Y, Levine P, Lin E, Glaser S, Alpini G and Meng F: The functional role of microRNAs in alcoholic liver injury. J Cell Mol Med 18: 197-207, 2014.

22. Wei Y, Nazari-Jahantigh M, Neth $P$, Weber $C$ and Schober A: MicroRNA-126, -145, and -155: A therapeutic triad in atherosclerosis? Arterioscler Thromb Vasc Biol 33: 449-454, 2013.

23. Farooqi AA, Qureshi MZ, Coskunpinar E, Naqvi SK, Yaylim I and Ismail M: miR-421, miR-155 and miR-650: Emerging trends of regulation of cancer and apoptosis. Asian Pac J Cancer Prev 15: 1909-1912, 2014

24. Wang B, Majumder S, Nuovo G, Kutay H, Volinia S, Patel T, Schmittgen TD, Croce C, Ghoshal K and Jacob ST: Role of microRNA-155 at early stages of hepatocarcinogenesis induced by choline-deficient and amino acid-defined diet in C57BL/6 mice. Hepatology 50: 1152-1161, 2009.

25. Pogribny IP, Starlard-Davenport A, Tryndyak VP, Han T, Ross SA, Rusyn I and Beland FA. Difference in expression of hepatic microRNAs miR-29c, miR-34a, miR-155, asnd miR-200b is associated with strain-specific susceptibility to dietary nonalcoholic steatohepatitis in mice. Lab Invest 90: 1437-1446, 2010.

26. Livak KJ and Schmittgen TD: Analysis of relative gene expression data using real-time quantitative PCR and the 2(-Delta Delta C(T)) Method. Methods 25: 402-408, 2001.

27. Guan TM, Liu DC, Wang JF, Cai S, Lin MJ, Lu RR, Wu KF, Ma XL, Wu T and Li WD: Protective effect of extract from fruit of Clausena lansium (Lour.) Skeels against acute alcohol-induced hepatotoxicity in mice. Zhong Guo Yao Li Xue Yu Du Li Xue Za Zhi 26: 829-834, 2012 (In Chinese).
28. Le HS and Bar-Joseph Z: Integrating sequence, expression and interaction data to determine condition-specific miRNA regulation. Bioinformatics 29: i89-i97, 2013.

29. Hou YN, Zhang XL and Wu HH: Effect of rifampicin and isoniazid coadministration on the metabolism and pharmacokinetics of isoniazid in mice. Jie Fang Jun Yao Xue Xue Bao 27: 23-26, 2011 (In Chinese).

30. Wang K, Zhang S, Marzolf B, Troisch P, Brightman A, Hu Z, Hood LE and Galas DJ: Circulating microRNAs, potential biomarkers for drug-induced liver injury. Proc Natl Acad Sci USA 106: 4402-4407, 2009.

31. Ceppi M, Pereira PM, Dunand-Sauthier I, Barras E, Reith W, Santos MA and Pierre P: MicroRNA-155 modulates the interleukin-1 signaling pathway in activated human monocyte-derived dendritic cells. Proc Natl Acad Sci USA 106: 2735-2740, 2009.

32. Lu F, Weidmer A, Liu CG, Volinia S, Croce CM and Lieberman PM: Epstein-Barr virus-induced miR-155 attenuates NF-kappaB signaling and stabilizes latent virus persistence. J Virol 82: 10436-10443, 2008.

33. Kuo YC, Li YS, Zhou J, Shih YR, Miller M, Broide D, Lee OK and Chien S: Human mesenchymal stem cells suppress the stretch-induced inflammatory miR-155 and cytokines in bronchial epithelial cells. PLoS One 8: e71342, 2013.

34. Nazari-Jahantigh M, Wei Y, Noels H, Akhtar S, Zhou Z, Koenen RR, Heyll K, Gremse F, Kiessling F, Grommes J et al: MicroRNA-155 promotes atherosclerosis by repressing Bcl6 in macrophages.J Clin Invest 122: 4190-4202, 2012.

35. Tili E, Michaille JJ, Cimino A, Costinean S, Dumitru CD Adair B, Fabbri M, Alder H, Liu CG, Calin GA and Croce CM: Modulation of miR-155 and miR-125b levels following lipopolysaccharide/TNF-alpha stimulation and their possible roles in regulating the response to endotoxin shock. J Immunol 179: 5082-5089, 2007

36. Miller AM, Gilchrist DS, Nijjar J, Araldi E, Ramirez CM, Lavery CA, Fernández-Hernando $\mathrm{C}$, McInnes IB and Kurowska-Stolarska M: MiR-155 has a protective role in the development of non-alcoholic hepatosteatosis in mice. PLoS One 8: e72324, 2013.

37. Senior JR: Alanine aminotransferase: A clinical and regulatory tool for detecting liver injury-past, present, and future. Clin Pharmacol Ther 92: 332-339, 2012.

38. Yamaura Y, Nakajima M, Takagi S, Fukami T, Tsuneyama K and Yokoi T: Plasma microRNA profiles in rat models of hepatocellular injury, cholestasis, and steatosis. PLoS One 7: e30250, 2012.

39. An FM, Yu DS, Xie Q, Gong BD, Wang H, Guo Q and Yu H: The role of miR-122 expression during the acute liver failure in mice induced by D-GalN/LPS. Zhonghua Gan Zang Bing Za Zhi 18: 527-532, 2010 (In Chinese)

40. Jopling C: Liver-specific microRNA-122: Biogenesis and function. RNA Biol 9: 137-142, 2012.

41. Wagner AE, Boesch-Saadatmandi C, Dose J, Schultheiss G and Rimbach G: Anti-inflammatory potential of allyl-isothiocyanate - role of Nrf2, NF-(k) B and microRNA-155. J Cell Mol Med 16: 836-843, 2012. 